\section{Effects of the topical application of an ethyl acetate fraction from Vernonia scorpioides on excisional wounds infected with Staphylococcus aureus in rats}

\author{
Maria Regina Orofino Kreuger, *,1 Bruna Gonçalves Farias, ${ }^{1}$ \\ Janaína Moreira, ${ }^{1}$ Luise Zozula Blind, ${ }^{2}$ Solomon Kweku Sagoe \\ Amoah, ${ }^{3}$ Andreia Siqueira Leite, ${ }^{3}$ Maique Weber Biavatti, ${ }^{3}$ Tom \\ van Hoof, ${ }^{4}$ Katharina D'Herde, ${ }^{4}$ Alexandre Bella Cruz ${ }^{1}$
}

\author{
${ }^{I}$ Núcleo de Investigações Químico-Farmacêuticas, Centro de Ciências da Saúde, \\ Universidade do Vale do Itajai, Brazil; \\ ${ }^{2}$ Departamento de Farmacologia, Setor de Ciências Biológicas, Centro Politécnico, \\ Universidade Federal do Paraná, Curitiba, Brazil; \\ ${ }^{3}$ Laboratório de Farmacognosia, Departamento de Ciências Farmacêuticas, Centro \\ de Ciências da Saúde, Universidade Federal de Santa Catarina, Brazil; \\ ${ }^{4}$ Department of Human Anatomy, University of Ghent, Belgium.
}

Revista Brasileira de Farmacognosia Brazilian Journal of Pharmacognosy 22(1): 123-130, Jan./Feb. 2012

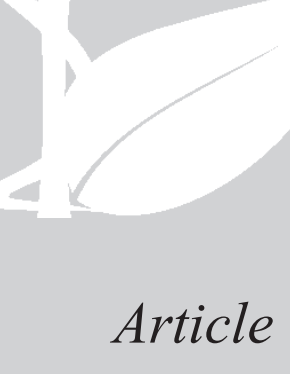

Received 24 Jan 2011

Accepted 20 May 2011 Available online 21 Oct 2011

Keywords: Vernonia scorpioides ethyl acetate fraction wound healing

Staphylococcus aureus

ISSN 0102-695X http://dx.doi.org/10.1590/S0102$695 \times 2011005000192$

\section{Introduction}

The tribe Vernonieae belongs to the family Asteraceae, and includes sesquiterpene lactones. There are about 200 species of Vernonia in Brazil, some of which are traditionally used in folk medicine (Lopes, 1991). Different biological effects of the sesquiterpene lactones species from Vernonia are described. The decoction of $V$. amygdalina showed to be a safe and moderately clinically effective treatment for malaria in adult semi-immune patients with no severe adverse events (Challand \& Willcox, 2009); the seeds from $V$. anthelmintica possess antidiabetic and antihyperlipidemic properties without evident toxic effects (Fatima et al., 2010); V. amygdalina extracts exhibit anti tumor activity (Oyugi et al., 2009); methanol extract from $V$. cinerea demonstrates anti-inflammatory properties (Pratheeshkumar \& Kuttan, 2009); and V. amygdalina ethanol and aqueous extracts inhibited the growth of Staphylococcus aureus (Gram-positive) and Escheriachia coli (Gram-negative) and showed activity against Candida albicans (Okigbo \& Mmeka, 2008).

Vernonia scorpioides (Lam.) Pers., Asteraceae, is very common in Brazil and usually grows in poor, deforested soils (Cabrera \& Klein, 1980). Previous studies of $V$. scorpioides crude extract and its derived chloroform and hexane fractions have shown fungicide and moderate bactericide activity (Freire et al., 1996), and its use as a treatment for mange (scabies) has been recorded (Lans et al., 2001). In mice, the dichloromethane fraction $(5 \mathrm{mg} / \mathrm{kg})$ from the crude extract totally inhibited tumor development (Pagno et al., 2006), while subfraction 2125 from the crude extract $(5 \mathrm{mg} / \mathrm{kg})$ inhibited tumor growth in the Sarcoma 180 ascitic tumor model in mice (Kreuger et al., 2009). The topical use of its alcoholic extract (200 $\mathrm{mg}$ of the $V$. scorpioides hydrogel) showed mild wound healing effects in rats when the wounds were treated 
topically for 30 days (Leite et al., 2002), although noninfected skin ulcers treated with an ointment $20 \%$ of the crude concentrated extract from $V$. scorpioides with solid Vaseline and lanoline (1:2) showed toxicity for the tissues when applied immediately after the incision in mice. The daily treatment presented enlarged damaged areas in the skin wounds after seven days, when compared with the control. However, this concentration did not inhibit the influx of mononuclear leukocytes, the proliferation of fibroblasts, or the formation of blood vessels observed after fourteen days (Dalazen et al., 2005).

Foot complications are common in diabetic patients; foot ulcers are among the more serious consequences. These ulcers frequently become infected, and if not treated promptly and appropriately, diabetic foot infections can lead to septic gangrene and amputation. Staphylococcus aureus is the most common pathogen in these infections, and the increasing incidence of methicillin-resistant $S$. aureus (MRSA) over the past two decades has further complicated antibiotic treatment (Nicolau \& Stein, 2010). Treatment of MRSA can include use of antibiotics; topical therapies such as honey, topical silver, and gentian violet; and bacteriophages (Durai et al., 2010). In human skin ulcer, a significant increase in MRSA was detected, where S. aureus was the predominant organism (Harrington et al., 2010). There is an urgent need to find new drugs that will be effective against bacteria that are resistant to the currently available antibiotic therapy.

Infection is a well-recognized barrier to healing, and multiple variables contribute to its development (Bowling et al., 2009). Inflammation and healing are processes that are extremely complex and intricate, and is disorganized in chronic non-healing ulcers on the legs. The healing process involves the interaction of multiple groups of cells, extracellular matrix molecules and growth factors, and is affected by vascular insufficiency, the severity of the injury, and the presence of infection. The antimicrobial treatment of tissues after injury is determined by the mechanism of injury, time from injury to treatment, wound contamination, pathogenicity of colonizing bacteria in the lesion, and factors relating to the patients themselves (Lipsky et al., 2006). The ideal therapy for skin ulcers would suppress excessive inflammation and increase the power of healing (Daróczy, 2006).

We studied the development of the wound healing in an established cutaneous wound healing model infected with $S$. aureus and treated with ethyl acetate III (EAIII) obtained from $V$. scorpioides. We then evaluated their effects on the parameters of healing in rats, quantifying the extent of wound contraction, damaged tissue, granulation tissue, and re-epithelization in a quantifiable fashion.

\section{Materials and Methods}

\section{Plant material}

Flowers and leaves of Vernonia scorpioides (Lam.) Pers., Asteraceae, were collected from wild specimens of "restinga" forest (a type of coastal tropical and subtropical moist broadleaf forest) in NavegantesSC, Brazil), in September 2006, and identified by Dr. Ana Claudia Araújo of the Universidade do Vale do Itajaí. A voucher specimen (M. Biavatti 11) was deposited at the Barbosa Rodrigues Herbarium, Itajaí, Santa Catarina, Brazil.

\section{Extract, fractions and sample preparation}

Flowers and fresh leaves of $V$. scorpioides $(5 \mathrm{~kg})$ were extracted with ethanol $(18 \mathrm{~L})$ at room temperature, in the absence of light, for thirty days. The ethanol was then removed using a rotary evaporator. $1 / 3$ of water $(2 \mathrm{~L})$ was added to the crude extract obtained, and the extract was submitted to liquid-liquid fractioning using solvents with increasing polarities. The respective fractions obtained were denominated: $n$-hexane I (HEX I, $16.16 \mathrm{~g}$ ), dichloromethane I (DCM I, $136 \mathrm{~g}$ ), ethyl acetate I (EA I, $560 \mathrm{mg}$ ), and water. The dichloromethane I fraction was initially subjected to silica gel column chromatography (CC) (60-230 mesh) eluted with $n$-hexane, followed by dichloromethane, ethyl acetate and methanol, yielding subfractions for each of the four solvents: $n$-hexane (HEX II, $320 \mathrm{mg}$ ), dichloromethane (DCM II, $84 \mathrm{~g}$ ), ethyl acetate (EA II, $560 \mathrm{mg}$ ). The dichloromethane II subfraction was subjected to silica gel CC (230-400 mesh) and eluted again with $n$-hexane, followed by dichloromethane, ethyl acetate and methanol, yielding new subfractions of each of the four solvents (III series).

\section{Microorganism, media and inocula}

For the antimicrobial evaluation, S.aureus ATCC 6538P was used, a strain from the American Type Culture Collection (ATCC), Rockville, MD, USA. The bacteria were cultivated on Mueller-Hinton agar (MHA-Difco) at $35{ }^{\circ} \mathrm{C}$ for $24 \mathrm{~h}$. Cell suspension in saline $(0.86 \%)$ was adjusted to give a final concentration of $1.5 \times 10^{8}$ cell $/ \mathrm{mL}$, standardized with 0.5 on the McFarland scale $(\lambda=530 \mathrm{~nm})$ (NCCLS, 2006).

\section{Quantitative antimicrobial evaluation in vitro}

The minimum inhibitory concentration (MIC) was determined by the agar dilution method, according to reported procedures (Campos et al., 2007), which was carried out on slants $(1 \mathrm{~mL})$. Stock solutions of ethyl acetate III (EAIII) in dimethylsulfoxide (DMSO) was 
diluted to give serial two-fold dilutions, which were added to medium (MHA), resulting in concentrations ranging from 0.010 to $10 \mathrm{mg} / \mathrm{mL}$. Afterwards, a volume of $1 \mu \mathrm{L}$ of inoculum suspension, prepared previously, was added to each slant, with the exception of the sterile control, and incubated at $35{ }^{\circ} \mathrm{C}$ for $24 \mathrm{~h}$. The final concentration of DMSO in the assay did not exceed $2 \%$. A drug-free solution was used as blank control. Each assay was repeated three times. The MIC was defined as the lowest concentration of compound at which the microorganism tested did not demonstrate visible growth. The minimum bactericidal concentration (MBC) was defined as the lowest concentration yielding negative subcultures.

\section{Animals}

Eighteen Wistar rats (250-300 g) obtained from the Central Animal Facility of Univali, were used (six animals per group). They were kept in individual cages in standard environmental conditions, with free access to water and standard pellet food. The animals were used after an acclimatization period of seven days and the experiments were conducted in accordance with the Univali Ethics Committee. All procedures involving animals were approved by the institutional committee on the care and use of animals at our institution (protocol number 172/08, CEP-UNIVALI).

\section{Excision wound model and histopathological analysis}

The animals were anesthetized with Ketamine 2\% (König Laboratories-Brazil) and Xilazine 6\% (Calier Laboratories-Brazil). The back of each rat was shaved and the skin excised using a round biopsy incisor (Stiefel Laboratories-USA), to obtain a wound area of $5 \mathrm{~mm}$.
Each lesion received a suspension containing $50 \mu \mathrm{L}$ of inoculum of $S$. aureus. $24 \mathrm{~h}$ after infection, the animals were divided into three groups, according to the treatment, Group I ( $\mathrm{n}=5)$, topical application with $50 \mu \mathrm{L}$ of EAIII ( 5 $\mathrm{mg} / \mathrm{kg}$ ), Group II ( $\mathrm{n}=5)$, topical application with $50 \mu \mathrm{L}$ of rifamycin diethylamide B (Rifocin $\mathrm{M}^{\circledR}$ ) $25 \mathrm{mg}$, group III $(\mathrm{n}=5)$ topical application with $50 \mu \mathrm{L}$ of saline solution, for seven days. The animals were then sacrificed, after being anesthetised and infused through the left ventricle with $0.9 \%$ saline solution and subsequently, with $10 \%$ formalin solution. The lesions were surgically removed and the skin specimens were fixed in $10 \%$ buffered formaldehyde and embedded in paraffin wax. After routine pathological procedures, sections of $5 \mu \mathrm{m}$ in thickness were mounted on slides and stained with hematoxylin and eosin (HE). The slides were examined under light microscopy by a specialized pathologist. A single blind evaluation of two sets of serial sections from each lesion was carried out. A reticule eyepiece with 100 squares was used to measure the percentage of the damaged area, granulation tissue and epithelium regeneration, at a magnification of $10 \mathrm{x}$ using an optical microscope. The averages of three sets were determined. The ulcer size and histopathological grading scores were also recorded.

\section{Analysis of ulcer contraction}

The wounds on the backs of the rats were treated daily and measured at the end of each treatment. The two largest dimensions of each lesion were measured using a digital caliper and the area was calculated in $\mathrm{mm} 2$. The final measure was subtracted from the initial value $(5 \mathrm{~mm})$ and the result was considered the value of the contraction.

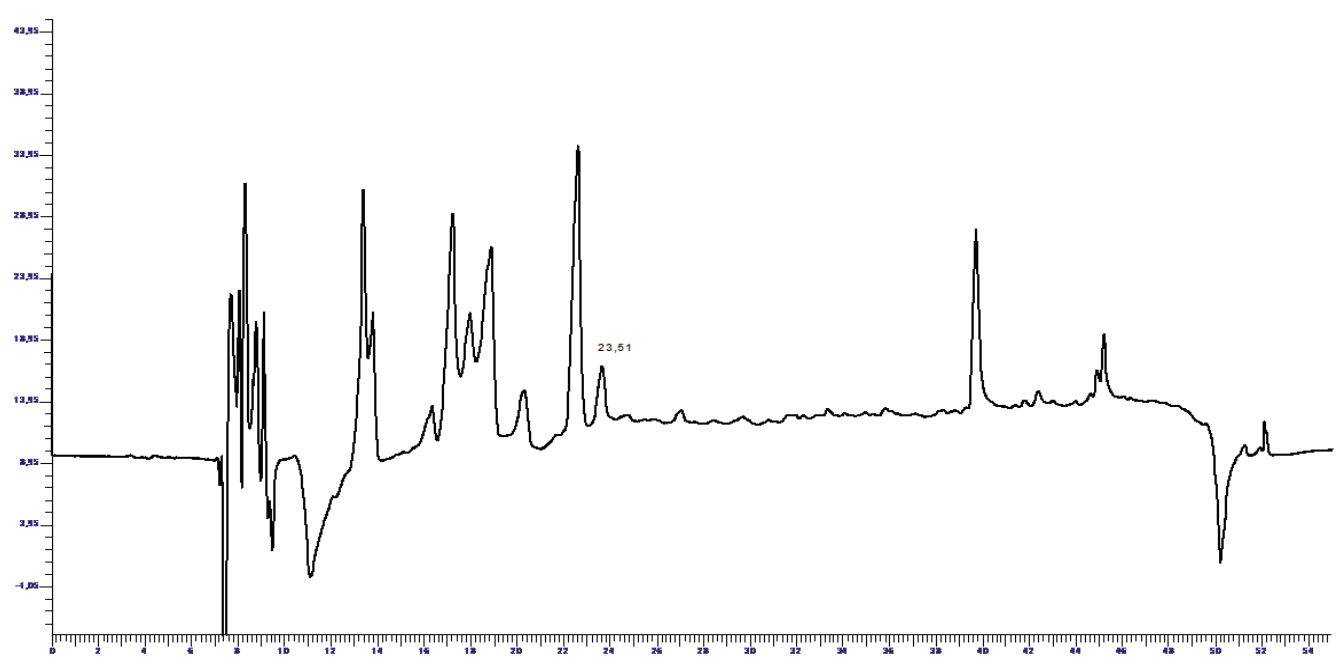

Figure 1. HPLC chromatogram of the ethyl acetate (EAIII) fraction of Vernonia scorpioides (260 $\mathrm{nm}$ ). The peak at $23.51 \mathrm{~min}$ is the sesquiterpene lactone diacethylpiptocarphol. 


\section{Statistical analysis}

Significant differences were compared using analysis of variance (ANOVA) and Tukey's test. The level of significance was determined at $p<0.05$.

\section{HPLC analysis of EAIII}

The fraction and the reference compound (diacethylpiptocarphol) $(100 \mu \mathrm{g} / \mathrm{mL})$ were analysed on a Synergi Fusion-RP $(250 \times 4.6 \mathrm{~mm}, 5 \mu \mathrm{m})$ column (Phenomenex). The solvent system was composed of A (acetonitrile) and $\mathrm{B}$ (water with $0.5 \%$ acetic acid), with an elution program performed as follows: $0-5 \min 20 \%$ of A, $6-35 \mathrm{~min} 20 \%$ to $80 \%$ of A; $3540 \mathrm{~min}, 20 \%$ of A; kept for $10 \mathrm{~min}$. The total analysis time was $50 \mathrm{~min}$ and the flow rate was of $0.8 \mathrm{~mL} / \mathrm{min}$. The injection volume was $20 \mu \mathrm{L}$, with detection at $260 \mathrm{~nm}$. The HPLC instrument was a Perkin Elmer (200 series) equipped with an UVVis detector. Data analyses were carried out using the TotalChrom software (Perkin Elmer).

\section{Results}

The effects of $V$. scorpioides infected skin ulcers were determined by observing the development of the lesions after seven days of treatment with ethyl acetate III. The contraction of the wound healing and the histological evaluation showed that animals treated with EAIII obtained from $V$. scorpioides extract (Group I) presented faster wound healing, compared with animals treated with rifamycin (Group II) and saline solution $0.9 \%$ (Group III). After seven days, group I showed higher wound contraction and better histological findings than the other groups, such as absence of necrotic area and abscess, presence of granulation tissue, formation of new extracellular matrix, and epithelium repair. According to the HPLC conditions mentioned earlier, a chromatogram of the ethyl acetate III fraction was obtained (Figure 1). The previously isolated sesquiterpene lactone was not the major compound shown at this wavelength. The main compounds isolated from EAIII are diacethylpiptocarphol (1), ethyl caffeate (2), apigenin (3), luteolin (4) and the polyacetylene 5-(octa-2,4,6-triynyl)furan-2(5H)-one (5) (Buskuhl et al., 2009; 2010).

In vitro assay

Antibacterial activity of the EAIII was determined by the dilution agar assay, as this method is especially good for determining the relative potency of polar and non-polar substances, as well as all types of complex extracts. The results of minimal inhibitory and bactericidal concentrations (MIC and MBC) displayed values of 1.25 and $2.5 \mathrm{mg} / \mathrm{mL}$, respectively.

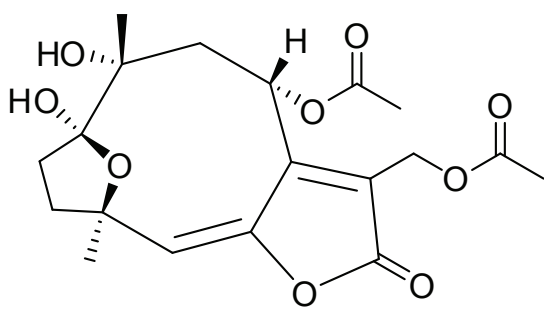

1<smiles>CCOC(=O)/C=C/c1ccc(O)c(O)c1</smiles>

2<smiles>[R]c1cc(-c2cc(=O)c3c(O)cc(O)cc3o2)ccc1O</smiles>

$3 \mathrm{R}=\mathrm{H}$

$4 \mathrm{R}=\mathrm{OH}$

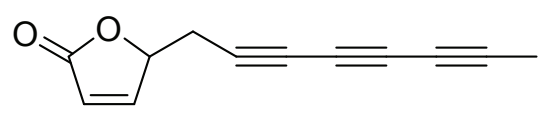

5

\section{Analysis of wound contraction}

After seven days, lesions treated with the EAIII presented greater wound contraction $(3.01 \mathrm{~mm})$, compared with the treatment with rifamycin $(1.96 \mathrm{~mm})$ and saline solution $(1.6 \mathrm{~mm})$. The value was considered statistically significant $(p<0.005)$ when comparing the group treated with the studied fraction with the group treated with rifamycin and saline solution (Figure 2).

Histological analysis of necrotic tissue, clotting and crust

Ulcers treated with EAIII (Group I) presented less damaged area, verified by the presence of necrotic tissue, clotting and crust, compared with the treatment of the other two groups. All the lesions from groups II and III presented necrotic tissue, and in group I, only one ulcer still showed damaged area (Figure 3 ). The value was considered statistically significant $(p<0.05)$ in relation to the group treated with saline solution, after seven days of 
treatment daily, observed in the wound sections stained with HE. (Figures 4A, 4B and 4C)

Histological analysis of granulation tissue and new extracellular matrix formation

The treatment with EAIII from $V$. scorpioides and the treatment with rifamycin presented similar formation of granulation tissue after seven days, the proportions of tissue formation being lower compared with the treatment with saline solution, due of the larger area of contraction, particularly in the group treated with EAIII (Figure 2), and also because the treated lesions showed a higher percentage of new extracellular matrix and connective tissue with fibrosis compared with the other groups (Figure 3). However the values were not considered statistically significant. Granulation tissue and new extracellular matrix formation can be verified by the wound sections stained with HE, in which the connective tissue showed mild fibrosis and a higher amount of inflammatory cells in the lesions that received saline solution, compared with the other treatments. (Figures 4A, 4B and 4C).

\section{Histological analysis of wound re-epithelialization}

For the epithelial tissue analysis, the width of the wound covered by epithelial cells was taken into account.
Total epithelium repair was observed in the treatment with EAIII, except in one ulcer. Treatment with rifamycin showed similar results, but with the presence of some ulcers with two-thirds of its width covered by epithelium $(\mathrm{n}=2)$ and in the group treated with saline solution $0.9 \%$, most of the ulcers presented repair of less than one third of the epithelium width $(n=4)$, (Figure 3). These microscopic findings were confirmed by histological assessment of wound re-epithelialization (Figure 4A, 4B and $4 \mathrm{C})$.

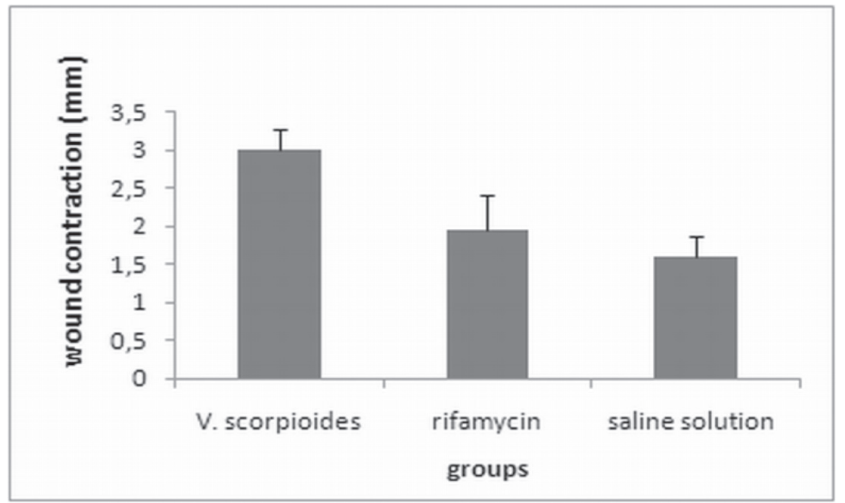

Figure 2. Effect of the application of EAIII, rifamycin and saline solution on cutaneous wound closure rate. The data for wound closure are expressed in millimeters $(\mathrm{mm})$. All data are mean SD $p<0.005$ different from Vernonia scorpioides-treated wounds in control animals.
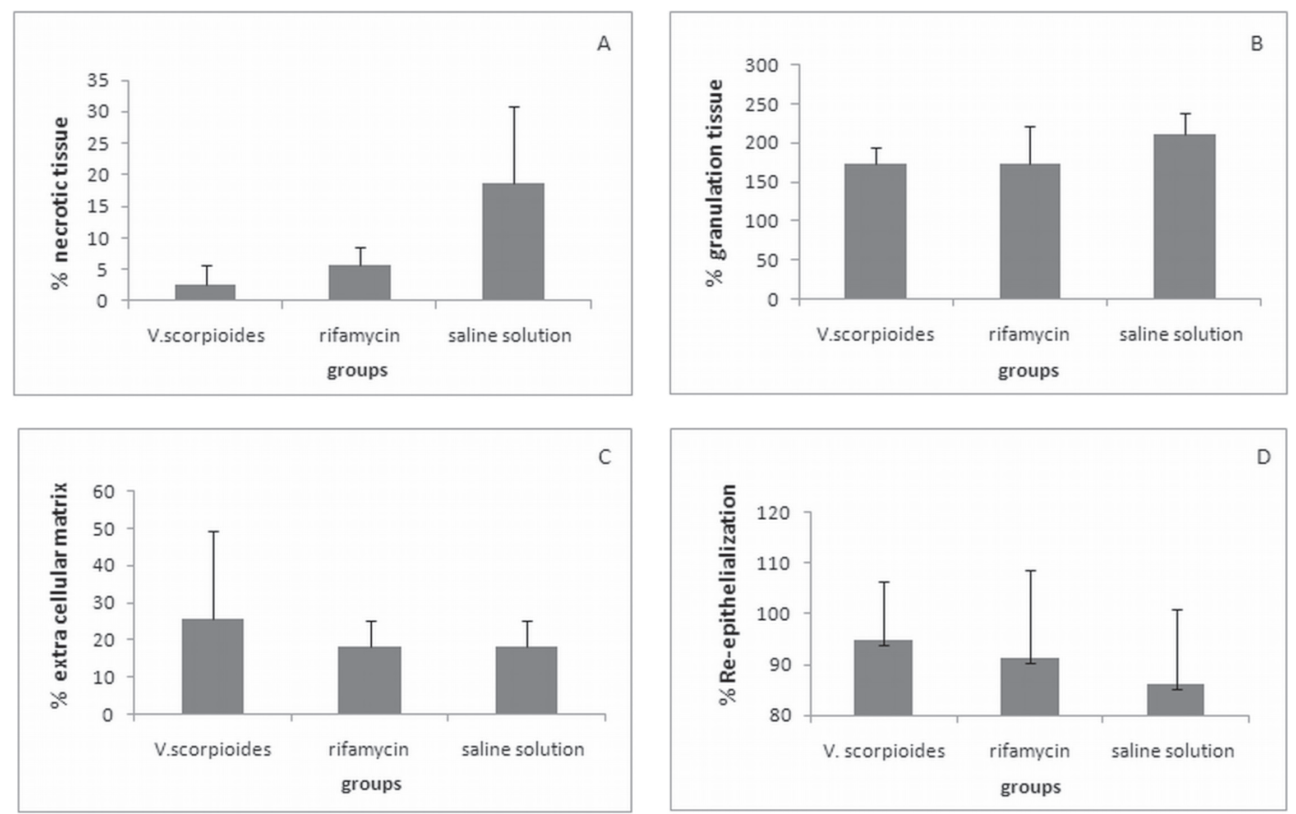

Figure 3. Percentage of necrotic tissue (A), granulation tissue (B), new extracellular matrix formation (C) and re-epithelialization (D). The ulcers were treated with EAIII, rifamycin and saline solution examined seven days after induction. The value for necrotic tissue was considered statistically significant $(p<0.05)$ in relation to the treated group and control (rifamycin) compared with the group treated with saline solution. The data corresponds to the mean of the three areas examined, at a magnification of $10 \mathrm{x}$ $(\mathrm{n}=5)$. 


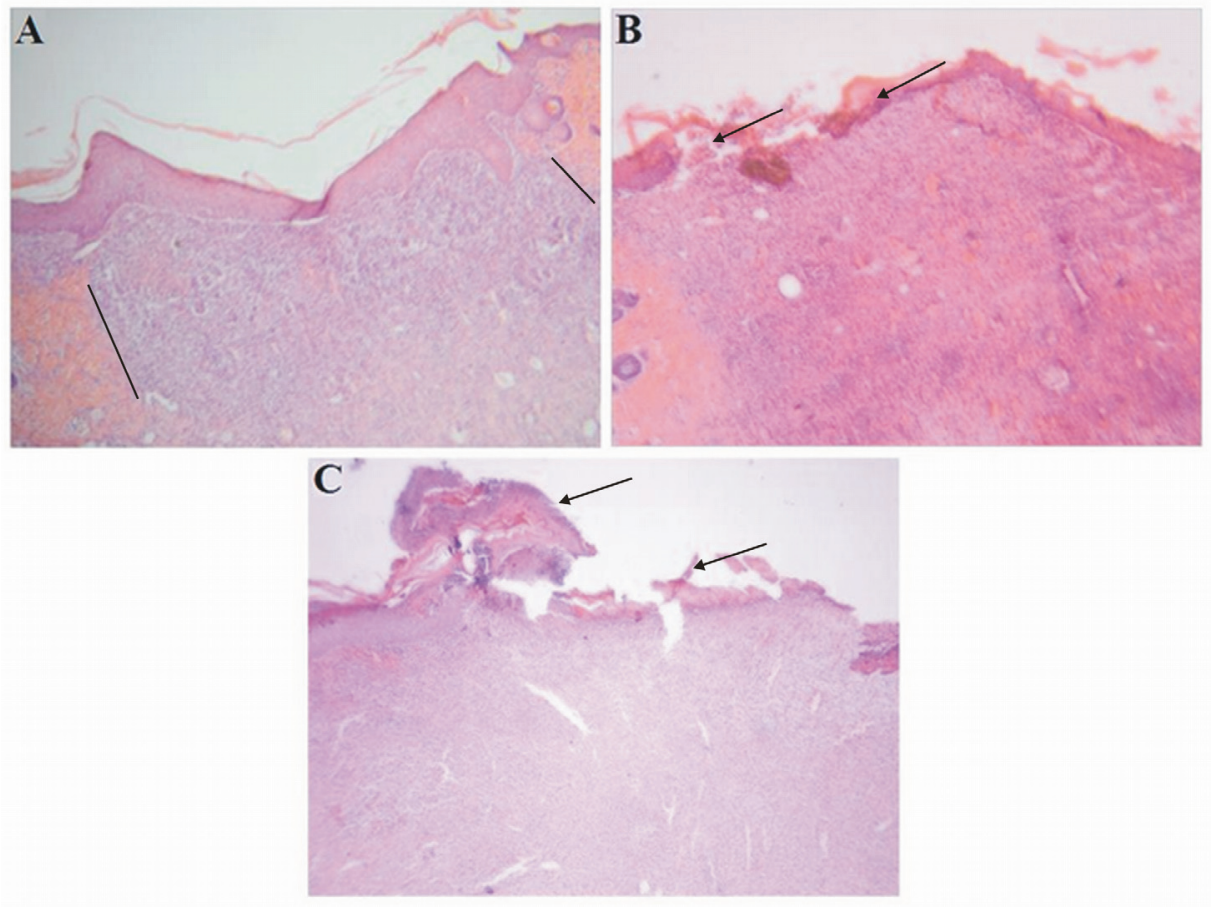

Figure 4. Wound healing seven days after experimental skin excision under different treatment conditions: (A) At both sides, the rim of the wound can be seen (lines) in the lesion treated with EAIII of Vernonia scorpioides, indicating greater wound contraction compared with the rifamycin treatment $(\mathrm{B})$ and the saline solution treatment $(\mathrm{C})$. In $\mathrm{B}$ and $\mathrm{C}$, more necrosis and interrupted epithelium (arrow) can be seen, as well as more extensive formation of granulation tissue in C. (HE- 4x).

\section{Discussion}

Wound healing is characterized by reepithelialization, granulation tissue growth and remodeling of extracellular matrix. Although the wound healing process occurs by itself, spontaneously, and does not require much help, there are various risk factors such as infection, supply of blood, nutritional status and other factors that influence the resolution of this process (Lipsky et al., 2006). It is well known that attack by microbes, which invade the skin barrier, delays the natural woundhealing process (Pattanayak \& Sunita, 2008). MRSA is increasing in infections and is a serious threat to patients in health care facilities and the community. Resistance to common antibiotics makes treating MRSA costly and difficult. The main end point observed in this study wound contraction and collagen synthesis were clearly accelerated by treating the wounds with EAIII, although all the parameters observed (presence of necrotic tissue, clotting and crust, re-epithelialization and granulation tissue growth) were affected, suggesting a pro-healing activity of this studied fraction. Topical application of $V$. scorpioides EAIII at the wound site produced significant wound healing activity, indicating that plant compounds can have an antibacterial effect, based on the fact that the formation of abscesses on the ulcer surface in vivo was not observed. The studied fraction also promoted antibacterial activity in vitro, but there is little information available on the antimicrobial property of $V$. scorpioides. Bardón et al. (2007) tested antimicrobial activity of several plants by the diffusion method, and showed that extracts of this plant presented activity against $S$. aureus. These results were corroborated in our findings. In Brazilian folk medicine, topical application of the ethanol extract of fresh leaves of $V$. scorpioides is used to treat various skin disorders, including chronic wounds and ulcers. Ulcers of the lower limb and foot frequently become infected with $S$. aureus, which is the most common pathogen in these infections (Nicolau \& Stein, 2010) and if it is not treated promptly and appropriately, the treatment becomes more difficult, because the infection presents a barrier to healing (Bowling et al., 2009). It was demonstrated that non-infected skin ulcers treated with crude extract of $V$. scorpioides showed toxicity to the tissues when applied immediately after non-infected incision in mice (Dalazen et al., 2005). The crude extract can be dangerous in the initial wound healing stage in non-infected lesions, but our results showed that in infected ulcers this is not the case, indicating a possible antibacterial activity of $V$. scorpioides compounds. In the tribe Vernonieae (family: Asteraceae) sesquiterpene lactones (Lopes, 1991) are found, for which the different 
biological effects are described. The data suggest that these compounds have anti-inflammatory and anti-ulcer (Feltenstein et al., 2004), anti-malarial (Chung \& Moon, 2009), and antibacterial (Ntutelaa et al., 2009, Saroglou et al., 2010) properties. These results could be related to the $\alpha, \beta$-unsaturated carbonyl groups in these compounds, which seems to be important for their cytotoxicity (Lee et al., 1971). The EAIII evaluated in this work was phytochemically investigated in parallel, revealing the presence of sesquiterpene lactones (glaucolides and hirsutinolides) such as diacethylpiptocarphol and related hirsutinolides, flavonoids and cinnamic acid derivatives (Buskuhl et al., 2010), and also a polyacetylene (Buskuhl et al., 2009) (Figure 1).

In conclusion, in our study, besides the antibacterial activity observed in vitro, the in vivo evaluations showed faster resolution of scars in ulcers infected with $S$. aureus and treated with $V$. scorpioides ethyl acetate III. These results support the effectiveness of $V$. scorpioides in infected wound healing in rats.

\section{Acknowledgements}

The authors are grateful to Maria de Lourdes Correa and Beatris Pacheco Correa for their technical support.

\section{References}

Bardón A, Borkosky S, Ybarra MI, Montanaro S, Cartagena E 2007. Bioactive plants from Argentina and Bolivia. Fitoterapia 78: 227-231.

Bowling FL, Jude EB, Boulton AJ 2009. MRSA and diabetic foot wounds: contaminating or infecting organisms? Curr Diabetes Rep 9: 440-444.

Buskuhl H, Blind LZ, Oliveira FL, Freitas RA, Barison A, Campos FR, Corilo Y, Eberlin MN, Caramori GF, Biavatti MW 2010. Sesquiterpene lactones from Vernonia scorpioides and their in vitro cytotoxicity. Phytochemistry 71: 1539-1544.

Buskuhl H, Freitas RA, Delle Monache F, Barison A, Campos FR, Corilo Y, Eberlin MN, Biavatti MW 2009. A new polyacetylene from Vernonia scorpioides (Lam.) Pers. (Asteraceae) and its in vitro antitumoral activity. $J$ Brazil Chem Soc 20: 1327-1333.

Campos MP, Cechinel Filho V, Silva RZ, Yunes RA, Monache FD, Bella Cruz A 2007. Antibacterial activity of extract, fractions and four compounds extracted from Piper solmsianum C.DC. var. solmsianum. Z Naturforsch 62: 173-178.

Cabrera AL, Klein RM 1980. Compostas: 3. Tribo: Vernoniae. Fl Ilustr Catarin 354-355.

Challand S, Willcox M 2009. A clinical trial of the traditional medicine Vernonia amygdalina in the treatment of uncomplicated malaria. J Altern Complem Med 15:
1231-1237.

Chung IL, Moon HI 2009. Antiplasmodial activities of sesquiterpene lactone from Carpesium cernum. J Enzym Inhib Med Ch 24: 131-135.

Dalazen P, Molon A, Biavatti MW, Kreuger MRO 2005. Effects of topical application of extract from Vernonia scorpioides on excisional wounds in mice. Rev Bras Farmacogn 15: 82-87.

Daróczy J 2006. Quality control in chronic wound management: the role of local povidone-iodine (Betadine) therapy. Dermatology 212: 82-87.

Durai R, Ng PC, Hoque H 2010. Methicillin-resistant Staphylococcus aureus: an update. AORN J 91: 599606.

Fatima SS, Rajasekhar MD, Kumar KV, Kumar MT, Babu KR, Rao CA 2010. Antidiabetic and antihyperlipidemic activity of ethyl acetate:isopropanol $(1: 1)$ fraction of Vernonia anthelmintica seeds in streptozotocin induced diabetic rats. Food Chem Toxicol 8: 495-501.

Feltenstein MW, Schühly W, Warnick JE, Fischer NH, Sufka KJ 2004. Anti-inflammatory and anti-hyperalgesic effects of sesquiterpene lactones from Magnolia and Bear's foot. Pharmacol Biochem Be 79: 299-302.

Freire MFI, Abreu HS, Cruz LCH, Freire RB 1996. Inhibition of fungal growth by extracts of Vernonia scorpioides (Lam.) Pers. Rev Microbiol 27: 1-6.

Harrington AT, Mahlen SD, Clarridge 3rd JE 2010. Significantly larger numbers of methicillin-resistant Staphylococcus aureus bacteria are recovered from polymicrobial respiratory and wound sites by use of chromogenic primary media than by use of conventional culture. $J$ Clin Microbiol 48: 1350-1353.

Kreuger MRO, Biavatti MW, Pacheco E, D'ávila Junior RR, Blind LZ 2009. Cytotoxic activity of the subfraction 2125 from Vernonia scorpioides against Sarcoma 180 tumor cells in mice. Rev Bras Farmacogn 19: 353-357.

Lans C, Harper T, Georges K, Bridgewater E 2001. Medicinal and ethnoveterinary remedies of hunters in Trinidad. BMC Complem Altern M 30: 1-10.

Lee KH, Huang ES, Piantadosi C, Pagano JS, Geissman TA 1971. Cytotoxicity of Sesquiterpene Lactones. Cancer Res 31: 1649-1654.

Leite SN, Palhano G, Almeida S, Biavatti MW 2002. Wound healing activity and systemic effects of Vernonia scorpioides extract in guinea pig. Fitoterapia 73: 496500.

Lipsky BA, Berendt AR, Deery HG, Embil JM, Joseph WS, Karchmer AW, LeFrock JL, Lew DP, Mader JT, Norden C, Tan JS 2006. Diagnosis and treatment of diabetic foot infections. Plast Reconstr Surg 117: 212S-238S.

Lopes JLC 1991. Sesquiterpene lactones from Vernonia. Mem I Oswaldo Cruz 86: 227-230.

NCCLS 2006. National committee for clinical Laboratory Standards: Methods for Dilution Antimicrobial Susceptibility Tests for Bacteria That Grow Aerobically, 
Approved Standard, 7th ed., Approved Standard M7A7, Wayne, Pennsylvania.

Nicolau DP, Stein GE 2010. Therapeutic options for diabetic foot infections: a review with an emphasis on tissue penetration characteristics. J Am Podiat Med Assn 100: 52-63.

Ntutelaa S, Smitha P, Matikab L, Mukindad J, Arendseb H, Allieb N, Estesf DM, Mabuselae W, Folba P, Steync L, Johnsone Q, Folkg WR, Sycede J, Jacobsb M 2009. Efficacy of Artemisia afra phytotherapy in experimental tuberculosis. Tuberculosis 89: 33-40.

Okigbo RN, Mmeka EC 2008. Antimicrobial effects of three tropical plant extracts on Staphylococcus aureus, Escherichia coli and Candida albicans. Afr J Tradit Complem 5: 226-229.

Oyugi DA, Luo X, Lee KS, Hill B, Izevbigie EB 2009. Activity markers of the anti-breast carcinoma cell growth fractions of Vernonia amygdalina extracts. Exp Biol Med 234: 410-417.

Pagno T, Blind LZ, Biavatti MW, Kreuger MRO 2006. Cytotoxic activity of the dichloromethane fraction from Vernonia scorpioides (Lam.) Pers. (Asteraceae) against Ehrlich's tumor cells in mice. Braz J Med Biol Res 39:
1483-1491

Pattanayak SP, Sunita P 2008. Wound healing, anti-microbial and antioxidant potential of Dendrophthoe falcata (L.f) Ettingsh, J Ethnopharmacol 120: 241-247.

Pratheeshkumar P, Kuttan G 2010. Modulation of immune response by Vernonia cinerea L. inhibits the proinflammatory cytokine profile, iNOS, and COX-2 expression in LPS-stimulated macrophages. Immunopharm Immunot 6: 1-11.

Saroglou V, Karioti A, Rancic A, Dimas K, Koukoulitsa C, Zervou M, Skaltsa H 2010. Sesquiterpene Lactones from Anthemis melanolepis and their antibacterial and cytotoxic activities. Prediction of their pharmacokinetic profile. J Nat Prod 73: 242-246.

\section{*Correspondence}

Maria Regina Orofino Kreuger

Núcleo de Investigações Químico-Farmacêuticas, Centro de Ciências da Saúde, Universidade do Vale do Itajaí.

Rua Uruguai 458, 88303-202, Itajaí, SC, Brazil.

mariaregina@univali.br

Tel.:+55 $4733417782 ; 33417564$ 